\title{
Applicability of two models of national identity on Kurds
}

\author{
Kawa AbdulKareem Sherwani ${ }^{a}$, and Bandar A. Mohammad \\ A \\ Media Technical Department, Erbil Technical College of Administration, Erbil \\ Polytechnic University, Kurdistan region of Iraq \\ 'balahaddin University - Erbil, Iraq / Kurdistan
}

Article History: Received: 11 January 2021; Accepted: 27 February 2021; Published online: 5 April 2021

\begin{abstract}
National identity is a broad concept. Anthony Smith (1991) and Shulman (2002) proposed two models and identified some components and elements as the building blocks of national identity. However, they both acknowledge the fact that their lists are not exhaustive and elements can be added or removed to or from the lists. Kurds, as the largest ethnic group without a state in the world, work very hard to establish a unified national identity as it is the first step of nation building. The study aims at the applicability of the two models on Kurds. Apparently, territory, language and culture are huge problems due to the limited access of different parts to others in different times.
\end{abstract}

Keywords: culture, Kurds; national identity; national identity elements; territory;

\section{Introduction}

The purpose of the study:

The study aims at applying the two models of national identity on Kurds as a nation without a state. National identity is one of the first steps of nation building and the study investigates how Kurds embody their national identity to the world. Each model identifies certain components and/or elements as the building blocks of national identity and the study analyzes them and applies them on Kurds to determine which one is well established and which ones are not.

Methodology:

First of all, the two models of national identity identify certain components and/or elements as the building blocks. They are applied on Kurds. As such, a detailed account of Kurds of Iraq is provided then the models are used as framework for the analysis of current status of Kurdistan and Kurds. For each element or component, real examples from Kurds and Kurdistan are provided to check their availability or not availability. At the end, the elements that are well established and grounded are identified. The study is an analysis of the status of Kurdish national identity under the light of the two models of national identity, which are (Smith, 1991) and (Shulman, 2002).

\section{Main Findings:}

From the application of the two models of national identity on Kurds, one can see that Kurds have their own government and parliament in their own region. However, neither the nature of the government nor the borders of the region are free dispute and are well recognized. Furthermore, Kurds are different in many aspects from the neighboring peoples and countries, one of which is their culture. However, culture can include many things like language, clothes, food and music.

\section{Social implications:}

The study, to the best of researchers' knowledge, can be of great importance for Kurds as they are on their way for establishing an independent state and their referendum in 2017 can be seen as evidence to support that. Furthermore, national identity can help nation building process.

Originality of the study:

Kurdish national identity is not grounded on solid basis as the poor literature on the topic can support that claim. As such, it is important to have more studies on Kurdish national identity to solidify the nature and status of national identity of Kurds and Kurdistan. To the best of our knowledge, there has been very few research on national identity of Kurds, except for some rare efforts like (Aziz, 2015) and (Sheyholislami, 2017).

\section{History of Kurds:}

Kurdish civilization dates back to the seventh millennium but some scholars and historians date their origin to the Median Empire in the sixth century BC (Minorsky, 1963, p. 43). Kurds are a group of people living in neighboring and somewhat adjacent territories in Iran, Turkey, Iraq and Syria, in an area that is known as (Kurdistan) which means (the homeland of Kurds). Kurdish population is estimated as about 30 million Kurds (Sherwani and Barlik, 2020). 
Throughout their existence, the exact number of Kurdish population is usually underestimated for political and economic reasons. The following is an estimated number of Kurds of Iraq, in different eras and times:

Table 1 Estimates of Iraqi Kurdistan's population (Aziz, 2015, p.9)

\begin{tabular}{|c|c|c|c|}
\hline No. & $\begin{array}{l}\text { Author(s) / } \\
\text { sources }\end{array}$ & Year & Estimated population \\
\hline 1 & League of nations & 1925 & 500,000 \\
\hline 2 & M. Amin Zaki & 1945 & 600,000 \\
\hline 3 & Jwaideh & 1953 & $1,200,000$ \\
\hline 4 & Nikitine & 1956 & 749,000 \\
\hline 5 & Edmond & 1957 & 900,000 \\
\hline 6 & Ghassemlou & 1965 & $3,300,000$ \\
\hline 7 & $\begin{array}{l}\text { Short and } \\
\text { McDermott }\end{array}$ & 1977 & $3,400,000$ \\
\hline 8 & Bruinessen & 1978 & $2,500,000$ \\
\hline 9 & More & 1984 & $3,000,000$ \\
\hline 10 & McDowall & 1992 & $4,100,000$ \\
\hline 11 & Nezan & 1996 & $5,200,000$ \\
\hline 12 & O’Shea & 1996 & $4,400,000$ \\
\hline 13 & Stansfield & 2003 & $3,315,204$ \\
\hline 14 & Muller and Lenzy & 2007 & $4,000,000$ \\
\hline
\end{tabular}

According to the World Factbook (2013), more than 14 million Kurds live in Turkey (25\% of the total population of Turkey), 6 millions in Iraq (23\% of the whole population), 8 millions in Iran (10\%), and 2 millions in Syria (9\% of the Syrian population). As such, they have been looked at as minorities and strangers in these countries and faced oppression and assimilation by the host countries. Kurds resisted assimilation and fought back everywhere to varying degrees. All their hardship and resistance have gone in vain in the sense they have not been able to establish a state of their own, with the exception of the short lived state of (Mahabad Republic) in Iran whose autonomy was declared on January 22nd, 1946 and collapsed after about 11 months (wikipedia). No wonder the Kurds are usually referred to as "a non-state nation" ( ) because, undoubtedly, they have almost all the characteristic features of statehood except for a state.

However, the origin and history of Kurds are of much debate. The territory of Kurds has, historically, been the scene of numerous battles, flow of various peoples, conquerors, and armies. Each one of these groups has affected the race, culture, and language of the mountain dwellers and inhabitants. The traces of the effects of the various groups are evident in the physique and language of the Kurds (Jwaidah, 2006, p.11). In other words, Kurds are a group of indigenous people coming from different origins and each leaving some traces and having some effects. They have been fighting for decades, if not centuries, to get recognized and have a name and an independent identity and state.

As mentioned earlier, the host countries attempted to assimilate Kurds within their country and nation by denying their rights and oppressing them, the governments of these countries have tried to challenge Kurds and create obstacles for them and keep them from establishing and/or reinforcing their identity and culture (Karbasian, 2013, p.9). Nevertheless, the Kurds have some areas of national identity fixed and recognized and shared by all the Kurds, 
such as: the Kurdish language, their homeland of Kurdistan and certain beliefs and practices like clothes, music, dance... etc.

By and large, Kurds do not see any future in the host countries and have always tried to be independent in some form. One reason for their seeking of independence is to escape from the oppression and to feel safe. However, it is not an easy task. There are things that Kurds need to do first. Nation building has a lot of components and having a unified and established national identity is one of them. But what is national identity?

\section{National Identity:}

People want to show, improve, and preserve who they are. It is not only language that can be utilized to display who we are and "how we want people to see use" (Paltridge, 2012, p.9). Our clothes, gestures, behavior, and interactions affect how we show our identity. Our thoughts, attitudes, values, beliefs, feelings and understanding influence how people see us too.

Oxford Advanced Learners Dictionary (2005) defines identity as "2 the characteristics, feelings or beliefs that distinguish people from others". This raises a very important point about national identity which is that though national identity groups people with certain shared features and characteristics, it also sets them apart compared to the national identity of those who do not share the exact same characteristics. National identity is a collective group identity that is different from personal identity.

Taylor and Spencer (2004, p.4) state that

Identity is a work in progress, a negotiated space between ourselves and others; constantly being re-appraised and very much linked to the circulation of cultural meanings in a society. Furthermore identity intensely political. There are constant efforts to escape, fix or perpetuate images and meanings of others. These transformations are apparent in every domain, and the relationships between these constructions reflect and reinforce power relations.

In other words, identity is not stable in the sense it is subject to reshaping, redefining and remaking in different contexts. Identity has a strong relation with power. Hence, power is not fixed either.

National identity is hard to pin down due to the complexity and difficulty of explaining what constitutes a nation. For example, a nation can be regarded as "a body of people who are conscious of having gone through something together" like revolutions, uprisings, wars, oppressions, libration, or any great event (Edilman and Wilson, 1997, p. 479). In other words, people who have shared experience (happy or sad) tend to grow a sense of togetherness that can be regarded as part of their collective identity. On the other side, Anderson considered nation and nationalism to be cognitive phenomena, and calls them "imagined communities" (1983: p.15). Similarly, nations are assumed to be "mental constructs" (Wodak, et al., 2009, p.3).

Governments tend to promote national identity because it paves the way for internal social unity and it also eases tensions between different ethnic groups. So, having a distinctive national identity can serve as a political card to stabilize the nation states by focusing on their unified national identity that surpasses ethnic diversity.

Noticeably, there are numerous and sometimes opposing views to what constitutes and signifies nationalism and national identity. Its unstable and specified nature makes it a challenging area of investigation for researchers (Mayall \& Cronin, 1998, p.3). Nevertheless, the basic elements of national identity are "an historic territory, or homeland, common myths and historical memories, a common mass public culture, and a common economy with territorial mobility for all members" (Smith, 1991, p.14). In other words, nations and national identity have five elements or constituents. First, they need to have a well-established and demarcated borders and territories where the people have lived for several generations. The second element is shared history or myths that the people can relate to. Third element of national identity is a shared culture. Oxford Advanced English Learner's Dictionary defines culture as "the customs and beliefs, art, way of life and social organization of a particular country or group". So, the accepted practices and behavior of people can be regarded as a shared mass culture. It is the task of public system of education and the mass media to ensure spreading and preserving a shared mass culture among people. The fourth element is about the rights and obligations of people. All the people, with no exceptions, have civic, legal, political, and socio-economic rights and duties. The fifth element, of course, is having "some common regulating institutions" (Smith, 1991, p.10).

People show their national identity linguistically and non-linguistically. Some of the aspects of national identity are evident in the different modes of communication used among people. Some other aspects, on the other hand, are reflected on the beliefs and behavior of the people. What differs humans (some nations more than others) from other creatures is that humans have regulating systems and institutions to various degrees.

National identity implies having some shared elements among people of a defined territory who have shared history, culture and memories and enjoy similar rights and duties regulated by a body or institutions.

Aziz (2015) holds that "historical memory, language and territory as characteristic features of Kurdish national identity play an important role in stimulating national historical consciousness and ethnic solidarity" (p.5). The shared and stable characteristic features of Kurds boost the pride and awareness to a collective national identity. 
However, national identity can be reinforced by being superior and active in every aspect and field. Kurdish identity, or Kurdayety, means "a shared culture, language, territory, set of symbols, memory and experience, and future political aspirations" (Sheyholislami, 2011, p.47). Hence, Kurds need to reiterate their shared and distinctive culture and territory along with their past experiences. Celebrating a common past that all Kurds are proud of can reinforce Kurdish national identity. However, it is challenging to identify the same repertoire of cultural and national incidents and components that all Kurds are proud of, due to geographical and political reasons.

Newspaper, and radio or cables play a crucial role in the formation, and reproduction of national identities. It can be stated that after 1991, a cross border trans-state Kurdish identity started to strengthen due to political developments, the expansion of Kurdish Diasporas, and the use of satellite/ television and the internet.

\section{Literature review:}

Aziz (2015) sheds light on Kurdish national identity through the lenses of ethnonationalism and how Kurds understand and see national identity in the Kurdistan region of Iraq. His study takes on Anthony Smith's model of national identity. To obtain the data, he distributed a 49 item questionnaire among university students (about 450 respondents) at Salahaddin University - Erbil and analyzed the data quantitatively. His most striking conclusion is that "modern nationalism for the Kurds since the 1990s may be regarded as a state-seeking and nation-building movement" (p.162).

His study is theoretical in the sense the questionnaire was distributed on college students to imply that it is the perspective of students as an integral part of the discourse of education, or higher education in particular. Our study, on the other hand, is about the discourse of social media from the viewpoint of text producers (Facebook page administrators) to explore what modes they use, what elements of national identity they tackle and what relation or functions they assign to the captions that accompany the images in the Facebook pages of some local TV channels.

Sheyholislami (2011) adopted multimodal discourse analysis to study about 200 hours of Kurdistan Television (KTV) obtained during the second half of 2005 along with a decade of internet data. As the title of the book might suggest (Kurdish identity, discourse and new media), the study focuses on the articulation of national identity in the discourse of the new media (television and internet "youtube", in particular). He concluded that "discourse is a social practise, simultaneously constitutive of and constituted by social structures, relations, and identities" (p.14). The discourse practices of KTV, mostly, are intended for "constructing and reproducing a cross-border Kurdish identity" (p.170).

He adopted the social semiotic approach of communication that is derived from Halliday's Functional grammar to determine the ideational, interpersonal and textual functions and analyze the discursive functions.

\section{Smith's model of national identity:}

As mentioned earlier, at the beginning Kurds resisted discrimination, marginalization and assimilation processes undertaken and intended to be undertaken by the host countries. Hence, Kurds lack a coherent national identity that all the members of Kurdistan (the big Kurdistan) are proud of and adopting.

Under the model of Anthony D. Smith (1991) for national identity, the people of any nation can be studied as possessing or lacking each of the elements. However, these elements are not exclusively exhausted but it seems like an explicit and thorough model.

First element of national identity is a historical territory or homeland and Kurds have long been living in the area known nowadays as Kurdistan. The borders, especially of Iraqi Kurdistan, are well established though there are some areas in Iraq that are labeled as disputed areas according to the Iraqi constitution. Apart from these disputed areas, there are other cities and towns which are purely and undoubtedly part of Kurdistan despite of Iraqi, Syrian, Iranian, and Turkish governments persistent efforts to change the demography of these places. One major plot of Baath regime was "Arabisation" process, the aim of which was to alter the demographic existence of Kurds and Arabs in some areas for political reasons.

Second element is "common myths and historical memories" and Historians and Kurds relate themselves to common origins and consider themselves "descendants of the Meds" ( ). They also have well known and famous myths and memories like the myth of (Zw'ak and Kawa the blacksmith), the 1991 uprising .

Third element is a "common mass public culture" and Kurds are culturally different from the other neighboring peoples and nations, despite having certain similarities. They have their own language (Kurdish) with its different variations, wear specific clothes, have their own beliefs and even reputation.

The fourth and fifth elements of national identity according to Smith's model are "common legal rights and duties for all members" and "a common economy with territorial mobility for members", respectively (Smith, 1991, p.14). Kurds have identified duties and recognizable regulating institutions like (parliament, sports union of Kurdistan, Olympic union of Kurdistan, ... etc). To a great extent, Kurds have rights to do what they want within the boundaries of law and their own constitution

\section{Shulman's model of national identity:}

There are many interpretations for the components of national identity. One has to admit "that many building blocks complement each other to construct the national identity" (p.127). Ethnic, cultural, civic and geographical perspectives encompass the key viewpoints for the national identity. Stephen Shulman (2002) thought we do not 
need to separate the components, especially the civic and ethnic ones. He proposed a model and selected the three elements of (civic, cultural and ethnic identity) as the complementary components of national identity. According to Shulman's model, each element is subdivided into certain components, as shown in the table below:

Table (2) Elements and components of national identity (Shulman, 2002, p.)

\begin{tabular}{|l|l|}
\hline Elements of national identity & components \\
\hline \multirow{2}{*}{ Civic identity } & Citizenship \\
& Territory \\
& Will and consent \\
& Political ideology \\
& Political institutions and laws \\
\hline Cultural identity & Religion \\
& Language \\
& Tradition \\
\hline Ethnicity & Ancestry \\
& race \\
\hline
\end{tabular}

The model, by all means, is not an inclusive one, as other components and even elements can be added to the model. Some of the components and elements are generic nouns like culture, and can encompass a lot of other elements. One other note is important to mention that there is no clear cut line between the components and elements. They are interwoven and interlinked and run into each other.

Civic identity is the first component because people are the foremost building block of any nation, whether it is in nation states or fragile states or nations without states like Kurdistan. Citizenship is manifested in the sense of belonging to a territory with a governing body. People, majority of them, think they have an integral part of the country and need to express it in the form of services, obligations and rights like participation in elections. In regional elections of Kurdistan, for Kurdistan parliament or city council, the turnout of people is not that big. However, when the election is for Iraqi government and parliament, the turnout is much higher as they think it helps their ethnicity if the percentage of turnout is higher. As mentioned earlier, citizenship is a basic right and "can serve as a strong foundation to bear and hold together the diversity of society... [However;] being a citizen can never be dependant on being part of a specific ethnic, religion or linguistic group" (p.156). Furthermore, people show their citizenship especially in national events like Nawroz (the first day of Kurdish Calendar, 21st of March) or when there is an election for Iraqi government. Territory, which is the second component in civic identity, is problematic for Kurds. Kurds have a territory but the borders of the region (Kurdistan) are not well-marked. There are certain areas on the edges of the region that are deemed disputed or contested areas according to Iraqi constitution and are co-run by Iraqi and Kurdistan governments. People have the will to choose anywhere they want to live or move throughout this region. The government of Kurdistan and its parliament have allowed Kurds to live, move and travel to anywhere in the region. Mobility is a virtue of the area. However, Kurds had some problems in the mid-1990s during the civil wars between the two ruling political parties (Democratic Party of "PDK" and Kurdistan Patriotic Union of Kurdistan "PUK"). The movement and mobility of people with affiliations to the political parties was a major issue at that time. Even in recent years, when there is a problem between the political parties, prominent members are denied access to certain areas (footnote about the two incidents "yusuf" and "mahmood sangawi"). Another problem with civic element, especially the citizenship and territory components, is the people who have dual citizenships. During the civil war and onward, a lot of Kurds migrated to Europe and other continents and had been living there since. It is not clear whether they should be considered to have Kurdish national identity or not. Their next generation and offspring from native citizens of their host countries are another problem, yet to be addressed. Diversity in many ways is a virtue of Kurdistan. There are a lot of variations of Kurdish language and distinctive cultural habits and elements throughout the region (Sherwani \& Mohammedamin, 2019).

Cultural identity is a complicated concept as the definition of culture varies and there is no one definition that fits the concept together. According to Shulman's model, culture encompasses language and traditions. Kurds have 
their own language that has distinctive features and is different from the languages spoken by the neighboring regions and countries like Arabic, Turkish and Persian. Kurdish language is not understandable by speakers of the other languages. It is a key indicator that it is a separate and independent language. However, Kurds do not have a unified standard language. The two main variations of Kurdish (Kirmanji and Sorani) have a lot of differences that, to some people, they are not even mutually intelligible.

Cultural identity, as mentioned before, encompasses language and traditions. However, "many nation-states have a national culture in food, music, celebrations, clothing styles, etc. identifying and celebrating these shared cultural features is an important first step in building nationhood" (Shulman, 2002, 157).

Ethnicity is sometimes used interchangeably with race. However, nowadays race has taken a narrower sense and is confined to physical characteristics only. Brown et al. (1998) conclude that "on the basis of the current data, however, the reported importance of skin color leads us to speculate that skin color may be used as the primary determinant of race" (p, 305). Skin color might be a good indicator of one's race. One can easily see that skin color is only one in a group of physical features that determine the race of a person. Shape of the eyes, height, physique, facial hair (especially, beard) can also be taken as indicators of a particular race. It is common nowadays that racially profiling people is not tolerated and profiling one based on racial features, especially skin color, is considered to be racially abusing one's identity and in some countries it is regarded as a felony. In other words, you will be charged if you address one's race. Ancestry, the other component of ethnicity in Shulman's model, is restricted to the issue of decendence.

\section{Conclusions:}

Kurdish national identity has a lot of features that resembles universal national identity. Kurds, as a large nation, have a language that is totally different from any other language. Kurds, especially in Iraq, have a distinctive culture that is reflected in their clothes, music, race, and beliefs. There are certain cities, whose majority population are Kurd and are run by Kurds themselves, Kurdistan of Iraq has its own parliament and government. However, the host countries do not permit a large body of Kurds to govern themselves because they see separistic attempts in other parts too. There is, arguably, an indirect understanding between the four host countries (Iraq, Turkey, Iraqn and Syria) not to allow Kurds to seek independence.

\section{References}

1. ANDERSON, B. R. O. (1991). Imagined communities: reflections on the origin and spread of nationalism. London, Verso.

2. Barthes, R. 1964. "The Structuralist Activity." From Essais Critiques, trans. R. Howard. In Partisan Review 34 (Winter):82-88.

3. Cronin, M. (Ed.), Mayall, D. (Ed.). (1998). Sporting Nationalisms. London: Routledge, https://doi.org/10.4324/9780203013243

4. CRYSTAL, D., \& CRYSTAL, D. (2008). A dictionary of linguistics and phonetics.

5. Dimopoulos, K., Koulaidis, V. \& Sklaveniti, S. Research in Science Education (2003) 33: 189. https://doi.org/10.1023/A:1025006310503

6. FAIRCLOUGH, N. (1992). discourse and social change. Cambridge, UK, Polity Press.

7. Fairclough, N. (1995). Critical discourse analysis. London: Longman.

8. Harris, Z.S. 1952, "Discourse Analysis: A Sample Text", in Language, vol. 28, no. 4, pp. 474--494. Linguistic Society of America.

9. Jan Blommaert, 2005, Discourse. A Critical Introduction. Cambridge University

10. Kawa Abdulkareem Sherwani, M. M. B. (2020). The Present Status of Kurdish Language in Turkey ; A Sociolinguistic Study of Van Community. Journal of Xi'an University of Architecture \& Technology, XII(Iii), 748-765.

11. Kress, G. (1985). Linguistic processes in sociocultural practice. Deakin, Australia: Deakin University

12. Kress, Gunther. (2003). Literacy in the New Media Age. Abingdon, Oxon: Routledge.

13. munication 9(1): 91-115.

14. Paltridge, Brian. 2012, Discourse analysis : an introduction / Brian Paltridge Blomsbury Academic London ; New York

15. Press, 299 pages, ISBN 05215353

16. Press.

17. Sherwani, K. A., \& Mohammedamin, A. Q. (2019). The Role of Text Analysis in Political Translation with Reference to Kurdish and English. International Journal of Psychosocial Rehabilitation, 23(02), 789-799.

18. Stubbs, M. (1983). Discourse Analysis: The Sociolinguistic Analysis of Natural Language. Chicago, IL: The University of Chicago Press.

19. Tan, Sabine. 2010. Modelling engagement in a web-based advertising campaign, Visual Com-

20. Van Dijk, T. A. (1997). Editorial: `Applied’ Discourse Studies. Discourse \& Society, 8(4), 451-452. https://doi.org/10.1177/0957926597008004001 
21. Wodak, R, De Cillia, R, Reisigl, M, Liebhart, K 2009, The Discursive Construction of National Identity. translated by Angelika Hirsch, Richard Mitten, Johann Wolfgang Unger, 2nd ed. edn, Edinburgh University Press, Edinburgh (18th ed.)

22. WODAK, R., \& MEYER, M. (2001). Methods of critical discourse analysis. London, SAGE. 